\title{
Rapid Development of Hepatocellular Carcinoma after Eradication of Hepatitis C Virus with Directly Acting Antiviral Treatment
}

\author{
Fakhar Ali Qazi Arisar*, Saeed Hamid \\ Section of Gastroenterology, Department of Medicine, The Aga Khan University, Karachi, Pakistan \\ Email: ^fakhar.qazi@aku.edu
}

How to cite this paper: Arisar, F.A.Q. and Hamid, S. (2018) Rapid Development of Hepatocellular Carcinoma after Eradication of Hepatitis C Virus with Directly Acting Antiviral Treatment. Open Journal of Gastroenterology, 8, 295-305.

https://doi.org/10.4236/ojgas.2018.89032

Received: August 13, 2018

Accepted: September 16, 2018

Published: September 19, 2018

Copyright (c) 2018 by authors and Scientific Research Publishing Inc. This work is licensed under the Creative Commons Attribution International License (CC BY 4.0).

http://creativecommons.org/licenses/by/4.0/

\section{Open Access}

\begin{abstract}
Hepatitis $\mathrm{C}$ is a major risk factor for the development of hepatocellular carcinoma (HCC), arising typically on a background of liver cirrhosis. Treatment of hepatitis $\mathrm{C}$ has been revolutionized by the addition of oral direct-acting antivirals (DAAs) with sustained virological response (SVR) rates above $90 \%$. There is a recent concern under debate about the increased risk of early HCC recurrence in patients with chronic hepatitis $\mathrm{C}$ who were treated with direct-acting antivirals. Nonetheless, these reports mostly focused on patients who were cirrhotic and were already treated for HCC. We report 4 cases of treatment naive, chronic hepatitis $\mathrm{C}$ patients who were treated with DAAs and rapidly developed infiltrative HCC despite achieving SVR. Moreover, in our scenario, one of the patients appeared clinically non-cirrhotic until he developed HCC.
\end{abstract}

\section{Keywords}

Direct Acting Antivirals, Hepatitis C, Hepatocellular Carcinoma, Hepatoma

\section{Introduction}

Chronic Hepatitis C virus (HCV) infected patients with advanced fibrosis/chronic liver disease (CLD) have an overall annual risk of 3.2\% for the development of hepatocellular carcinoma (HCC) [1]. Antiviral therapy has been available since the early 1990s. However, the SVR rates were unsatisfactory with interferon-based regimens particularly when advanced liver disease sets in [2]. Also, the side effect profile of interferon limits its use due to poor compliance [3]. Addition of direct-acting antivirals (DAAs) in the armamentarium has increased the HCV cure rates well above $90 \%$ even in patients with bridging fibro- 
sis or cirrhosis, with the additional advantage of avoiding side effects related with interferon. The occurrence of HCC is distinctly less in patients with cirrhosis who achieve sustained virological response (SVR) as compared to those who do not. However, this risk is not completely eliminated even after HCV remedy. There are case reports describing patients diagnosed with HCC up to 13 and even 20 years after successful antiviral therapy with interferon [4] [5]. Out of 500 patients treated with direct-acting antivirals (DAAs) from 2014 to 2017 at the Aga Khan University Hospital, Karachi, we present 4 cases with the rapid development of HCC even after achieving SVR with DAAs, of which all were treatment naive, while one appeared clinically non-cirrhotic until the development of HCC.

\section{Case 1}

A 64-year-old male was found to be HCV antibody positive on routine screening in November 2014. He was asymptomatic and physical examination was unremarkable. On investigations complete blood count (CBC) showed hemoglobin $(\mathrm{Hb}) 14.5 \mathrm{~g} / \mathrm{dl}$, total leukocyte count (TLC) $7.3 \times 10^{9} / \mathrm{L}$ and platelets $352 \times 10^{9} / \mathrm{L}$. Coagulation profile revealed prothrombin time (PT) of 10 seconds with INR 0.96. Liver functions exhibited a total bilirubin (TB) $1.6 \mathrm{mg} / \mathrm{dl}$, gamma-glutamyltransferase (GGT) $49 \mathrm{IU} / \mathrm{L}$, alanine transaminase (ALT) $63 \mathrm{IU} / \mathrm{L}$, alkaline phosphatase (ALP) $48 \mathrm{IU} / \mathrm{L}$ and serum albumin $4.3 \mathrm{~g} / \mathrm{dl}$. Viral profile depicted HCV RNA count of $6,454,981 \mathrm{IU} / \mathrm{ml}$, with genotype 3. HBsAg was non-reactive while $\mathrm{HBsAb}$ was reactive. Other investigations included creatinine $0.8 \mathrm{mg} / \mathrm{dl}$, TSH $1.032 \mu \mathrm{IU} / \mathrm{ml}$, HbA1c 8.3\%, fasting blood sugar $145 \mathrm{mg} / \mathrm{dl}$, cholesterol $120 \mathrm{mg} / \mathrm{dl}$, triglycerides $118 \mathrm{mg} / \mathrm{dl}$. Ultrasound showed a normalliver with regular margins. Portal vein measured $1.1 \mathrm{~cm}$ while spleen size was $9.4 \mathrm{~cm}$.

He was prescribed sofosbuvir and ribavirin for 24 weeks, which took around 6 months for him to get arranged as it was not freely available in Pakistan at that point in time. Treatment commenced in May 2015. A month after starting DAA, his PCR became negative and remained persistently negative at 3 months of treatment and at the end of treatment (October 2015). He also had improved his diabetic control during that period as his $\mathrm{HbAlc}$ improved sequentially to $6.0 \%$ and then $4.3 \%$ at the end of treatment. At the end of treatment (October 2015), bilirubin was $11 \mathrm{mg} / \mathrm{dl}$, ALT: $18 \mathrm{IU} / \mathrm{L}$, aspartate transaminase (AST): $22 \mathrm{IU} / \mathrm{L}$, Hb: $11.5 \mathrm{~g} / \mathrm{dl}$, TLC: $6.6 \times 10^{9} / \mathrm{L}$, and platelets: $429 \times 10^{9} / \mathrm{L}$. His Fib- 4 index was 0.79 while APRI score was 0.147 which ruled out significant fibrosis. Furthermore, he achieved SVR 12 (January 2016) as well as SVR 24 (April 2016) with normal ALT at both occasions.

In February 2017, he presented with dull aching right hypochondriac pain. Bilirubin was $1.7 \mathrm{mg} / \mathrm{dl}$. ALT was $82 \mathrm{IU} / \mathrm{L}$ and AST was $139 \mathrm{IU} / \mathrm{L}$, while platelets were $341 \times 10^{9} / \mathrm{L}$ making the Fib-4 index of 3.02 while APRI of 1.165 . Other labs showed Hb: 11.8 g/dl, TLC: $12.2 \times 109$ IU/L, GGT: 115 IU/L, ALP: 65 IU/L, Cr: $0.9 \mathrm{mg} / \mathrm{dl}$, Albumin: $3.7 \mathrm{~g} / \mathrm{dl}, \mathrm{PT}: 12.0 \mathrm{sec}$, INR: 1.1. U/S showed normal size liv- 
er with slight coarse echotexture and undulating margins. An ill-defined isoechoic area was seen in the left lobe of liver measuring $44.5 \times 41.9 \mathrm{~mm}$. Serum alpha-fetoprotein (AFP) was $4079 \mathrm{IU} / \mathrm{ml}$. His Childs score was 5 while MELD score was 10.

Triphasic CT scan showed irregular liver margins. A low-density lesion in the left lobe of liver around $50 \times 48 \mathrm{~mm}$ without any arterial enhancement and it remained low on all three phases of CT (Atypical HCC). A Patchy abnormal arterial enhancement was identified involving segment VI of the liver with washout on portal venous and delayed phase suggestive of infiltrative hepatoma. The Main portal vein appeared thrombosed with multiple collaterals representing cavernous transformation. Spleen appeared normal while no ascites was seen (Figure 1).

Due to the advance Barcelona clinic liver cancer (BCLC) stage of HCC, options for treatment were very limited. Hence patient was started on sorafenib as palliative treatment. A follow-up CT scan at 3 months interval showed anincrease in the size of left lobe lesion $(62 \times 70 \mathrm{~mm})$ with interval development of countless discrete areas of arterial enhancement and delayed washout in the entire liver parenchyma (Figure 2). He was last seen in June 2017 when he was

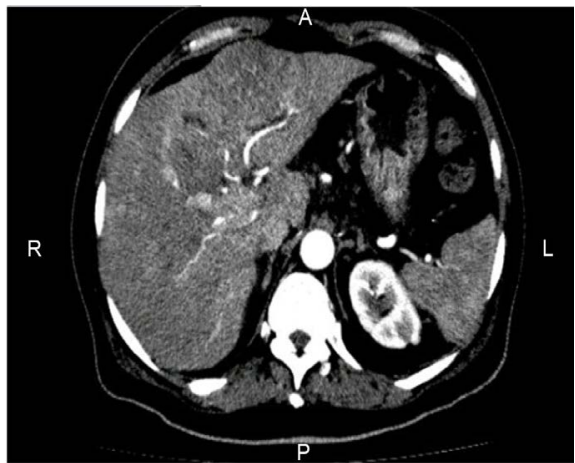

(a)

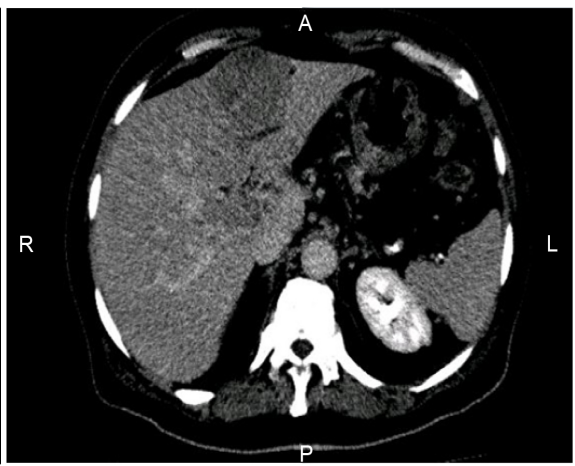

(b)

Figure 1. Hepatocellular carcinoma (Case 1). (a) Arterial phase. (b) Delayed phase.

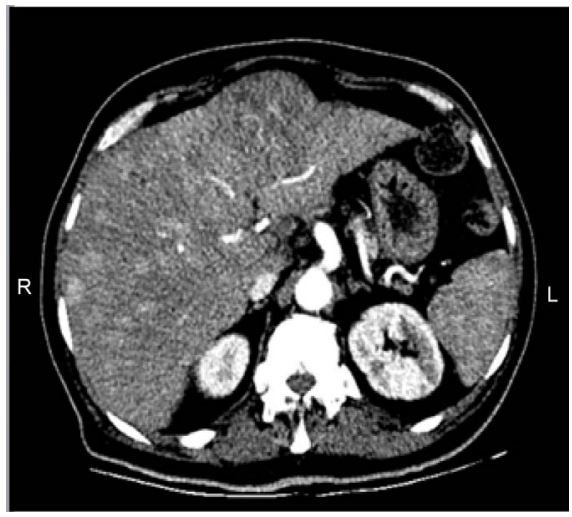

(a)

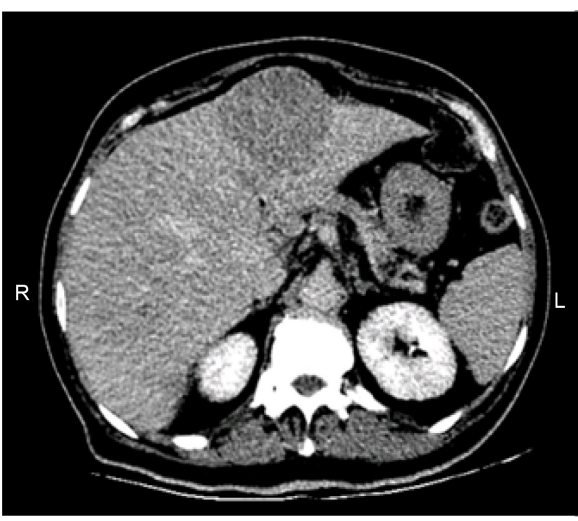

(b)

Figure 2. Hepatocellular carcinoma after 3 months (Case 1). (a) Arterial phase. (b) Delayed phase. 
admitted with encephalopathy, ascites and hepatorenal syndrome. Due to the guarded prognosis, he was kept for comfort care. Since there was no clinical improvement, the family took the patient home for the end of life care.

\section{Case 2}

A 74-year-old hypertensive female was found to be HCV antibody positive on routine screening in October 2014. She was asymptomatic and physical examination was unremarkable. On investigations complete blood count (CBC) showed hemoglobin $(\mathrm{Hb}) 13 \mathrm{~g} / \mathrm{dl}$, TLC $5 \times 10^{9} / \mathrm{L}$ and platelets $141 \times 10^{9} / \mathrm{L}$. Coagulation profile revealed prothrombin time (PT) of 13.3 seconds with INR 1.3. Liver functions exhibited a total bilirubin (TB) $1.5 \mathrm{mg} / \mathrm{dl}$, ALT $194 \mathrm{IU} / \mathrm{L}$, AST: $91 \mathrm{IU} / \mathrm{L}$ GGT $51 \mathrm{IU} / \mathrm{L}$, alkaline phosphatase $70 \mathrm{IU} / \mathrm{L}$ and serum albumin $3.8 \mathrm{~g} / \mathrm{dl}$. Viral profile depicted HCV RNA count of $150 \mathrm{IU} / \mathrm{ml}$, with genotype $3 . \mathrm{HBs} A g$ was non-reactive. Other investigations included creatinine $0.7 \mathrm{mg} / \mathrm{dl}$ and TSH $3.02 \mu \mathrm{IU} / \mathrm{ml}$. Ultrasound showed a normalliver with regular margins. Portal vein measured $1.0 \mathrm{~cm}$ while spleen size was $12.5 \mathrm{~cm}$. APRI score was 2.08 and FIB 4 was 3.38 .

She was started on sofosbuvir and ribavirin which she took for 24 weeks, from January 2015 to July 2015. During the course of treatment, she achieved rapid virological response (RVR) and end of treatment response (ETR), followed by SVR 12 (October 2015).

Her routine workup was done in May 2017 which showed Hb: $13.3 \mathrm{~g} / \mathrm{dl}$, TLC: $5.0 \times 10^{9} / \mathrm{L}$, platelets: $191 \times 10^{9} / \mathrm{L}$, bilirubin: $0.4 \mathrm{mg} / \mathrm{dl}$. ALT: $55 \mathrm{IU} / \mathrm{L}$, GGT: 288 IU/L, ALP: $121 \mathrm{IU} / \mathrm{L}, \mathrm{Cr}: 0.81 \mathrm{mg} / \mathrm{dl}$, Albumin: $3.5 \mathrm{~g} / \mathrm{dl}, \mathrm{PT}: 13.8 \mathrm{sec}$, INR: 1.15 . U/S showed nodular liver with Portal vein diameter of $1.1 \mathrm{~cm}$, spleen measuring $12.9 \mathrm{~cm}$ without any ascites.

In June 2017, she presented with nausea and weight loss. On examination, she had hepatomegaly with ascites. Repeat ultrasound due to recent onset ascites revealed multiple hypoechoic lesions in the liver, largest measuring $1.5 \times 1.2 \mathrm{~cm}$.

Triphasic CT scan showed cirrhotic liver with multicentric HCC in right lobe having an infiltrative pattern, $12 \times 9 \mathrm{~cm}$ in size, inseparable from the gallbladder. The right branch of the portal vein was thrombosed. Few lymph nodes were also seen near porta hepatis along with multiple soft tissue nodules in the lung suggestive of metastasis. Moderate ascites and multiple varices were also seen. Her AFP was $1100 \mathrm{IU} / \mathrm{ml}$.

Due to the advance BCLC stage of HCC, options for treatment were very limited. After a detailed discussion with the patient and family members, she was kept on supportive care only.

\section{Case 3}

A 42-year-old gentleman with a history of diabetes and hypertension came for evaluation of melena in June 2014. On workup, he was found to have HCV related CLD with grade-III esophageal varices for which he underwent band ligation. $\mathrm{He}$ 
had no other decompensation. Pertinent workup showed Hb: $12.1 \mathrm{~g} / \mathrm{dl}$, TLC: 6.8 $\times 10^{9} / \mathrm{L}$, Plat: $179 \times 10^{9} / \mathrm{L}$, INR: 0.97, Alb: $3.8 \mathrm{~g} / \mathrm{dl}$, TB: $1.1 \mathrm{mg} / \mathrm{dl}$, ALT: $85 \mathrm{IU} / \mathrm{L}$, GGT: 153 IU/L, AP: 115 IU/L, Genotype: 3, HCV PCR: 2,237,549 IU/ml, Cr: 0.8, HBsAg: Negative, and HbA1c: 9.0. U/S and CT scan of the abdomen showed cirrhotic liver with splenomegaly without any focal lesion or ascites. His MELD score was 7 and Child Pugh's score was 5/15. Relook EGD in August 2014 showed small varices. He took Sofosbuvir and ribavirin from January 2015 till June 2015 however, he didn't show up in the clinic until October 2016. At that time he was doing well, asymptomatic and labs were as follows: $\mathrm{Hb}: 13 \mathrm{~g} / \mathrm{dl}$, TLC: $2.1 \times 10^{9} / \mathrm{L}$, Plat: $95 \times 10^{9} / \mathrm{L}$, PT: $14.4 \mathrm{sec}$, INR: 0.9, TB: $0.4 \mathrm{mg} / \mathrm{dl}$, ALT: 46 IU/L, AST: 44 IU/L, GGT: 331 IU/L, ALP: 120 IU/L, Cr: 0.96 mg/dl, Alb: 4.6 $\mathrm{g} / \mathrm{dl}$, making MELD score of 6 . However, U/S showed a hypoechoic lesion in right lobe of liver which was later confirmed on CT scan (Figure 3 ) as multicentric HCC in segment IV $(45 \times 39 \mathrm{~mm}$, the segment I $(23 \times 27 \mathrm{~mm})$ and segment $\mathrm{V}(11 \times 5 \mathrm{~mm})$. His AFP was 2.93. He underwent trans-arterial chemo-embolization (TACE) in December 2016 after which he developed post-TACE syndrome which was treated conservatively. Follow up CT scan (Figure 4) in February 2017 showed residual enhancement in segment VI lesions as well as increased size in other lesions (segment I: $31 \times 33 \mathrm{~mm}$, segment V: $14 \times$ $6 \mathrm{~mm}$ ). His lab parameters make him child 7, MELD 6 and BCLC stage B. He has

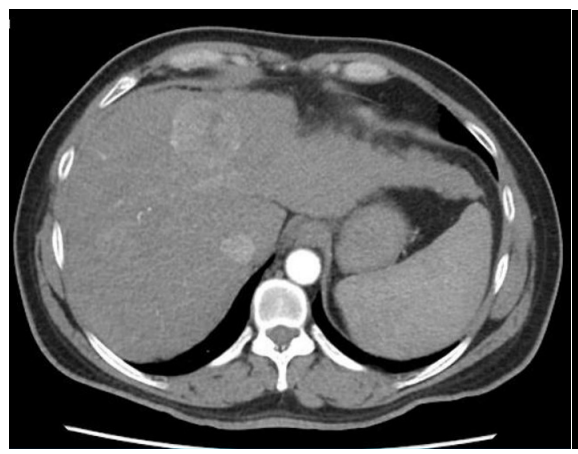

(a)

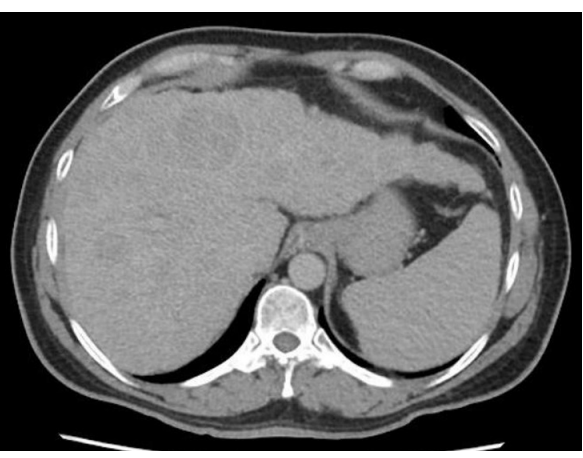

(b)

Figure 3. Hepatocellular carcinoma (Case 3). (a) Arterial phase. (b) Delayed phase.

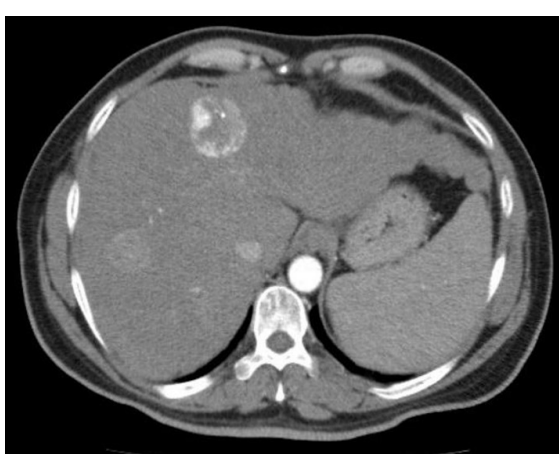

(a)

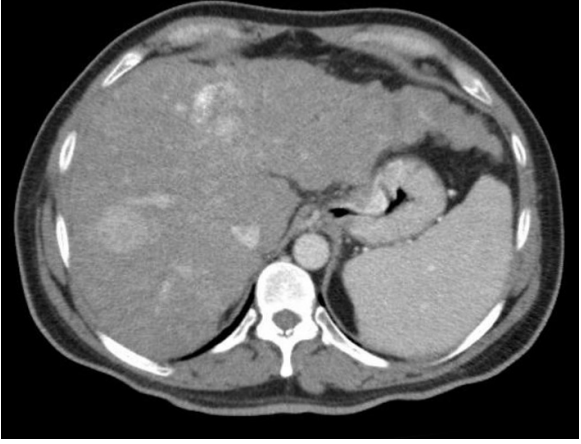

(b)

Figure 4. Hepatocellular carcinoma after TACE (Case 3). (a) Arterial phase. (b) Delayed phase. 
advisedthe second session of TACE which he was reluctant due to previous experience. Therefore, he was started on sorafenib. He was last seen in the clinic in March 2018, however, no imaging was performed as no intervention was planned.

\section{Case 4}

53-year gentleman with a history of diabetes was incidentally found to have HBsAg and Anti HCV antibody reactive in April 2014. He had a past history of Pott's disease for which he was treated with ATT for 18 months in 2008/2009. He was asymptomatic with the unremarkable examination. Workup showed: HCV RNA: 1,574,014 IU/ml, Genotype: 3, HBV DNA negative, HBeAg: negative, HBeAb: negative, TB: $1.3 \mathrm{mg} / \mathrm{dl}$, ALT: 90 IU/L, GGT: 93 IU/L, ALP: 133 IU/L, Alb: $3.7 \mathrm{~g} / \mathrm{d} / \ldots$ l, Hb: $12.9 \mathrm{~g} / \mathrm{dl}$, TLC: $7.1 \times 10^{9} / \mathrm{L}$, Plat $131 \times 10^{9} / \mathrm{L}$, Cr: 0.6 mg/dl, PT: $11 \mathrm{sec}$, INR: 1.12, HbAlc: $6.1 \%$, and Delta antibody: negative. US abdomen showed cirrhotic liver with portal vein diameter of $12 \mathrm{~mm}$ and normal spleen. His child score was 5 while MELD was 9 . He was started on sofosbuvir and ribavirin which he took from October 2014 till April 2015. During the treatment, he achieved RVR, EVR, EoTR. At the end of treatment, he also underwent screening EGD which showed small esophageal varices. In August 2015 he achieved SVR 12. During his routine visits, he remained asymptomatic. In May 2016 he achieved SVR 48. His surveillance EGD showed large varices in May 2016 for which EVBL was done. In November 2016 his labs were consistent with child 7 and MELD was 8. U/S ruled out any focal lesion or ascites. However, in 2017, he presented with a 1-week history of abdominal distension and scrotal swelling. Examination showed the presence of ascites. Workup showed

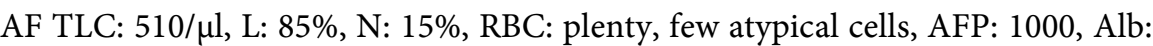
$2.6 \mathrm{~g} / \mathrm{dl}, \mathrm{Cr}: 0.7 \mathrm{mg} / \mathrm{dl}$, PT: $15 \mathrm{sec}$, INR: 1.23, Hb: $13.1 \mathrm{~g} / \mathrm{dl}$, TLC: $8.76 \times 10^{9} / \mathrm{L}$, Plat: $167 \times 10^{9} / \mathrm{L}$, and US revealed CLD with massive ascites and ahypoechoic mass lesion in right lobe of liver about $4 \times 3.7 \mathrm{~cm}$ in size. CT scan confirmed the presence of large HCC in right lobe with branch PV thrombus (Figure 5). $\mathrm{He}$ underwent TACE in January 2017. Follow-up CT showed a partial response of the disease (Figure 6) with AFP: 24,927. The second session of TACE was advised but the patient refused. He was last seen in May 2017 after which he lost

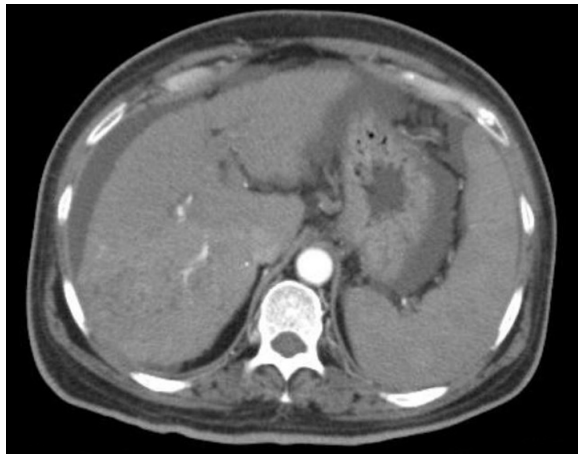

(a)

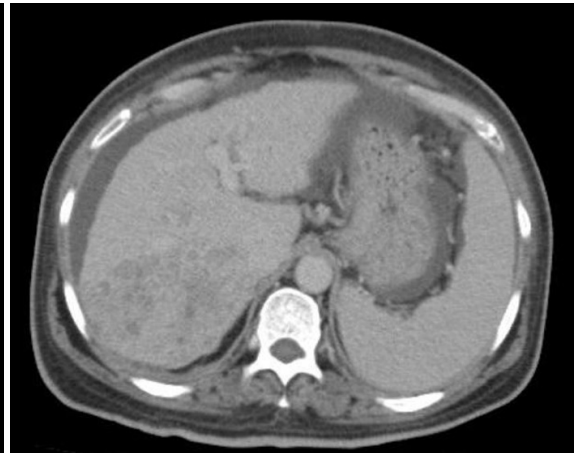

(b)

Figure 5. Hepatocellular carcinoma (Case 4). (a) Arterial phase. (b) Delayed phase. 


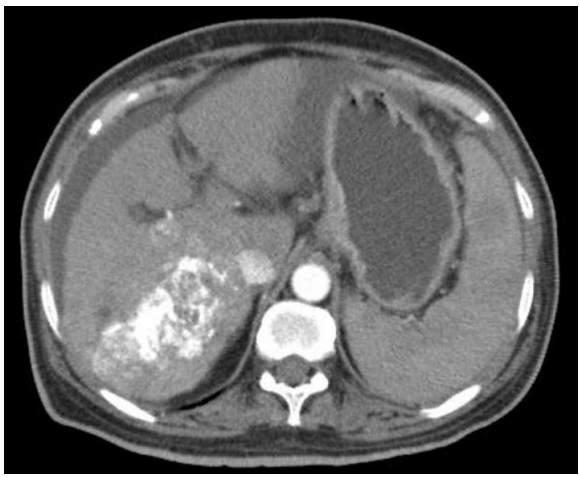

(a)

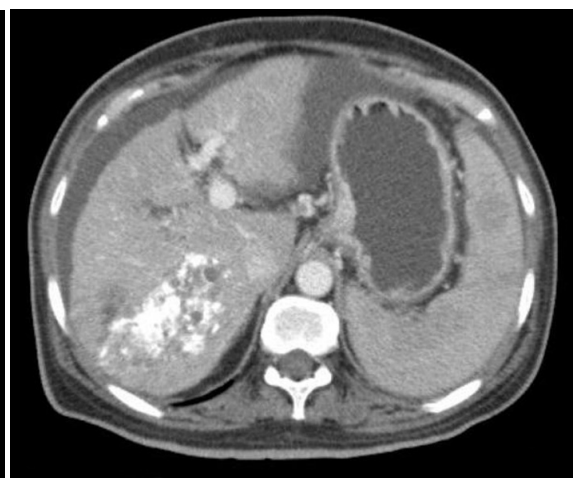

(b)

Figure 6. Hepatocellular carcinoma after TACE (Case 4). (a) Arterial phase. (b) Delayed phase.

follow-up.

\section{Discussion}

Eradication of HCV plays a key role in the prevention of HCC. A pooled analysis of 25,497 patients from 12 studies confirms that achievement of SVR reduces the risk of HCC (hazard ratio, 0.24 [95\% CI, $0.18-0.31$ ]; $\mathrm{p}=0.001$ ), with absolute risk reduction of $4.6 \%$ in patients achieving SVR (95\% CI, $4.2 \%-5.0 \%$ ) [6]. Nonetheless, the risk of HCC persists many years after SVR especially in high-risk patient i.e. those with established cirrhosis, old age, and diabetes. Consequently, they require surveillance for HCC despite SVR [7].

A few years back, DAAs were introduced in conjunction with interferon and ribavirin to promote their antiviral potential [8] [9]. Later they completely replaced interferon and ribavirin due to their better tolerance, even in older age group and cirrhotic patients, along with better safety profile, and are now considered the first line agents for HCV treatment [10] [11] [12]. However, data on long-term outcomes in cirrhotic patients treated with DAAs is still lacking.

A recent "note of caution" was provided by Reig et al. who interestingly showed an increased incidence of HCC with early recurrence after eradication of $\mathrm{HCV}$ with interferon-free therapy after successfully treated liver cancer (16 of 58 patients, 28\%) [13]. This postulate the idea that HCV elimination using DAAs may induce changes in the inflammatory status and immune response to tumors, leading to early recurrence. It is also hypothesized that DAA may enhance the growth of tiny/invisible HCC due to dysregulation of the immune system. This phenomenon is in contrast to interferon treatment which has its own immune-modulatory and anti-proliferative action [14].

Natural killer (NK) cells are the most prevalent innate immune cells in the liver. Chronic HCV infection is known to cause activation of NK cells along with increased expression of interferon-stimulated genes, hence enhancing the intrahepatic immune response. This intrahepatic immune activation is lost in patients treated with DAAs [15] [16]. Changes leading to liver regeneration which is associated with cure of inflammation and change in immunologic status can 
be responsible for the evolution of precancerous lesions into frank malignancy [17] [18].

Above findings of Reig et al. was later supported by few more researchers who confirmed that DAA-induced HCV eradication not only does not reduce HCC occurrence but have a high recurrence rate (29\%) within a short period of time (24 weeks) [18] [19] [20].

However, none of the three cohorts of French prospective multicenter ANRS showed an increase in HCC recurrence after DAA treatment in patients who underwent curative HCC therapies [21]. This was supported by English data where the author showed a reduction in HCC rate from $4 \%$ in untreated patients to $1.9 \%$ in patients with virus eradication, over 6 and 9 months respectively [22].

There is no head to head comparison except a retrospective analysis in patients who achieved SVR after interferon/ribavirin treatment vs DAAs treatment showing similar 3 and 5 year cumulative HCC development rates in both groups (1\% and $2.2 \%$ in Interferon group, and $1.3 \%$ and $3 \%$ in DAA, respectively) [23]. An indirect comparison of time to recurrence in patients with successfully treated early HCC and active HCV infection with those of patients with SVR by interferon-based and interferon-free regimens showed significantly lower time to recurrence in patients with active HCV infection compared with those with SVR both by interferon-free and interferon-based treatments. However, time to recurrence was similar in patients with SVR by interferon-free or by interferon-base strategies [24].

Reig et al. also raised concern about the pattern of tumor recurrence in patients treated with DAA [13], supported by another Italian cohort of cirrhotic patients who develop infiltrative patterns of HCC [25].

One of our patients was unique in that he achieved SVR and he appeared non-cirrhotic till he developed HCC a year after successful DAA therapy. In all of our patients, there was a rapid development of HCC, supported by recent negative imaging before the actual diagnosis. At the time of diagnosis, the tumor appeared infiltrative on CT scan with portal vein thrombosis making it advance staged. On follow up scan involvement of whole liver parenchyma within 3 months in case 1 also supports the speediness of tumor growth. This supports the concern raised by Reig and Roman in their group of patients. This also suggests that patients treated for HCV, despite being non-cirrhotic, should be kept in surveillance even after achieving SVR [26]. Due to the typical finding of tumor on CT scan, a biopsy was not done in any of the above patients.

In conclusion, there is a debatable increased risk of HCC occurrence/early recurrence in patients treated with DAAs. Our case series supports the existing data about the pattern of HCC occurrence after DAA therapy; however, large prospective studies are needed to solve this mystery.

\section{Conflicts of Interest}

Dr. Qazi Arisar has nothing to disclose. Dr. Hamid has nothing to disclose. 


\section{Financial Disclosure}

No funding source was involved.

\section{Informed Consent}

An informed written consent was obtained from all subjects.

\section{References}

[1] Singal, A.G., Volk, M.L., Jensen, D., Di Bisceglie, A.M. and Schoenfeld, P.S. (2010) A Sustained Viral Response Is Associated with Reduced Liver-Related Morbidity and Mortality in Patients with Hepatitis C Virus. Clinical Gastroenterology and Hepatology, 8, 280-288.

[2] Vezali, E., Aghemo, A. and Colombo, M. (2010) A Review of the Treatment of Chronic Hepatitis C Virus Infection in Cirrhosis. Clinical Therapeutics, 32, 2117-2138. https://doi.org/10.1016/S0149-2918(11)00022-1

[3] Livingston, S.E., Townshend-Bulson, L.J., Bruden, D.J., Homan, C.E., Gove, J.E., Plotnik, J.N., et al. (2016) Results of Interferon-Based Treatments in Alaska Native and American Indian Population with Chronic Hepatitis C. International Journal of Circumpolar Health, 75, Article ID: 30696. https://doi.org/10.3402/ijch.v75.30696

[4] Mashitani, T., Yoshiji, H., Yamazaki, M., Ikenaka, Y., Noguchi, R., Ishikawa, M., et al. (2009) Development of Hepatocellular Carcinoma in a Patient 13 Years after Sustained Virological Response to Interferon against Chronic Hepatitis C: A Case Report. Cases Journal, 2, 18. https://doi.org/10.1186/1757-1626-2-18

[5] Igarashi, G., Endo, T., Sawada, N., Mikami, K., Sato, K., Kudo, D., et al. (2015) Development of Hepatocellular Carcinoma in Chronic Hepatitis C Patients 20 Years after Achieving a Sustained Virological Response with Interferon Therapy: A Report of Two Cases. Journal of General and Family Medicine, 16, 199-203. https://doi.org/10.14442/jgfm.16.3_199

[6] Morgan, R.L., Baack, B., Smith, B.D., Yartel, A., Pitasi, M. and Falck-Ytter, Y. (2013) Eradication of Hepatitis C Virus Infection and the Development of Hepatocellular Carcinoma: A Meta-Analysis of Observational Studies. Annals of Internal Medicine, 158, 329-337.

[7] El-Serag, H.B., Kanwal, F., Richardson, P. and Kramer, J. (2016) Risk of Hepatocellular Carcinoma after Sustained Virologic Response in Veterans with Hepatitis C Virus Infection. Hepatology, 64, 130-137.

[8] Forestier, N., Reesink, H.W., Weegink, C.J., McNair, L., Kieffer, T.L., Chu, H.M., et al. (2007) Antiviral Activity of Telaprevir (VX-950) and Peginterferon Alfa-2a in Patients with Hepatitis C. Hepatology, 46, 640-648.

https://doi.org/10.1002/hep.21774

[9] Fried, M.W., Buti, M., Dore, G.J., Flisiak, R., Ferenci, P., Jacobson, I., et al. (2013) Once-Daily Simeprevir (TMC435) with Pegylated Interferon and Ribavirin in Treatment-Naive Genotype 1 Hepatitis C: The Randomized PILLAR Study. Hepatology, 58, 1918-1929. https://doi.org/10.1002/hep.26641

[10] American Association for the Study of Liver Diseases and Infectious Diseases Society of America (2016) HCV Guidance: Recommendations for Testing, Managing, and Treating Hepatitis C.

[11] European Association for the Study of the Liver (2017) EASL Recommendations on Treatment of Hepatitis C 2016. Journal of Hepatology, 66, 153-194.

[12] World Health Organization (2016) Guidelines for the Screening, Care and Treat- 
ment of Persons with Chronic Hepatitis C Infection.

[13] Reig, M., Mariño, Z., Perelló, C., Iñarrairaegui, M., Ribeiro, A., Lens, S., et al. (2016) Unexpected High Rate of Early Tumor Recurrence in Patients with HCV-Related HCC Undergoing Interferon-Free Therapy. Journal of Hepatology, 65, 719-726. https://doi.org/10.1016/j.jhep.2016.04.008

[14] Nault, J.-C. and Colombo, M. (2016) Hepatocellular Carcinoma Anddirect Acting Antiviral Treatments: Controversy after the Revolution. Journal of Hepatology, 65, 663-665. https://doi.org/10.1016/j.jhep.2016.07.004

[15] Llovet, J.M. and Villanueva, A. (2016) Liver Cancer: Effect of HCV Clearance with Direct-Acting Antiviral Agents on HCC. Nature Reviews Gastroenterology \& Hepatology, 13, 561-562. https://doi.org/10.1038/nrgastro.2016.140

[16] Serti, E., Chepa-Lotrea, X., Kim, Y.J., Keane, M., Fryzek, N., Liang, T.J., et al. (2015) Successful Interferon-Free Therapy of Chronic Hepatitis C Virus Infection Normalizes Natural Killer Cell Function. Gastroenterology, 149, 190-200.e2.

[17] Bruix, J., Gores, G.J. and Mazzaferro, V. (2014) Hepatocellular Carcinoma: Clinical Frontiers and Perspectives. Gut, 63, 844-855.

https://doi.org/10.1136/gutjnl-2013-306627

[18] Kozbial, K., Moser, S., Schwarzer, R., Laferl, H., Al-Zoairy, R., Stauber, R., et al. (2016) Unexpected High Incidence of Hepatocellular Carcinoma in Cirrhotic Patients with Sustained Virologic Response Following Interferon-Free Direct-Acting Antiviral Treatment. Journal of Hepatology, 65, 856-858.

https://doi.org/10.1016/j.jhep.2016.06.009

[19] Conti, F., Buonfiglioli, F., Scuteri, A., Crespi, C., Bolondi, L., Caraceni, P., et al. (2016) Early Occurrence and Recurrence of Hepatocellular Carcinoma in HCV-Related Cirrhosis Treated with Direct-Acting Antivirals. Journal of Hepatology, 65, 727-733. https://doi.org/10.1016/j.jhep.2016.06.015

[20] Cardoso, H., Vale, A.M., Rodrigues, S., Gonçalves, R., Albuquerque, A., Pereira, P., et al. (2016) High Incidence of Hepatocellular Carcinoma Following Successful Interferon-Free Antiviral Therapy for Hepatitis C Associated Cirrhosis. Journal of Hepatology, 65, 1070-1071. https://doi.org/10.1016/j.jhep.2016.07.027

[21] Pol, S. (2016) Lack of Evidence of an Effect of Direct-Acting Antivirals on the Recurrence of Hepatocellular Carcinoma: Data from Three ANRS Cohorts. Journal of Hepatology, 65, 734-740. https://doi.org/10.1016/j.jhep.2016.05.045

[22] Cheung, M.C., Walker, A.J., Hudson, B.E., Verma, S., McLauchlan, J., Mutimer, D.J., et al. (2016) Outcomes after Successful Direct-Acting Antiviral Therapy for Patients with Chronic Hepatitis C and Decompensated Cirrhosis. Journal of Hepatology, 65, 741-747. https://doi.org/10.1016/j.jhep.2016.06.019

[23] Kobayashi, M., Suzuki, F., Fujiyama, S., Kawamura, Y., Sezaki, H., Hosaka, T., et al. (2017) Sustained Virologic Response by Direct Antiviral Agents Reduces the Incidence of Hepatocellular Carcinoma in Patients with HCV Infection. Journal of Medical Virology, 89, 476-483. https://doi.org/10.1002/jmv.24663

[24] Petta, S., Cabibbo, G., Barbara, M., Attardo, S., Bucci, L., Farinati, F., et al. (2017) Hepatocellular Carcinoma Recurrence in Patients with Curative Resection or Ablation: Impact of HCV Eradication Does Not Depend on the Use of Interferon. Alimentary Pharmacology \& Therapeutics, 45, 160-168.

https://doi.org/10.1111/apt.13821

[25] Romano, A., Capra, F., Piovesan, S., Chemello, L., Cavalletto, L., Anastassopoulos, G., et al. (2016) Incidence and Pattern of "De Novo" Hepatocellular Carcinoma in HCV Patients Treated with Oral DAAs. 67 th Meeting of the American Association 
for the Study of Liver Diseases. Liver Meeting, Boston, 11-15 November 2016.

[26] Bertolini, E., Bassi, F. and Fornaciari, G. (2013) Development of Hepatocellular Carcinoma in a Non-Cirrhotic, Long-Term Responder to Antiviral Therapy, Chronic Hepatitis C Patient: What Kind of Surveillance? Annals of Gastroenterolo$g y, 26,80-83$. 